\title{
BMJ Open Critical care service delivery across healthcare systems in low-income and low-middle-income countries: protocol for a systematic review
}

\author{
Andrew George Lim (D) ,, ${ }^{1,2}$ Sean Kivlehan (1) ,3,4 Lia llona Losonczy, ${ }^{5}$ \\ Srinivas Murthy, ${ }^{6}$ Enrico Dippenaar, ${ }^{7}$ Richard Lowsby, ${ }^{8}$ \\ Marc Li Chuan L C Yang (D) , ${ }^{9}$ Michael S Jaung (i) , ${ }^{10} \mathrm{P}$ Andrew Stephens, ${ }^{11}$ \\ Nicole Benzoni, ${ }^{12}$ Nana Sefa, ${ }^{13}$ Emily Suzanne Bartlett, ${ }^{14}$ \\ Brandon Alexander Chaffay, ${ }^{15}$ Naeha Haridasa, ${ }^{16}$ Bernadett Pua Velasco, ${ }^{17}$ \\ Sojung Yi, ${ }^{18}$ Caitlin A Contag, ${ }^{19}$ Amir Lotfy Rashed, ${ }^{20}$ Patrick McCarville, ${ }^{15}$ \\ Paul D Sonenthal, ${ }^{21,22}$ Nebiyu Shukur, ${ }^{15}$ Abdelouahab Bellou, ${ }^{23}$ Carl Mickman, ${ }^{24}$ \\ Adhiti Ghatak-Roy, ${ }^{25}$ Allison Ferreira, ${ }^{26}$ Neill KJ Adhikari (1) , ${ }^{27}$ Teri Reynolds ${ }^{28}$
}

To cite: Lim AG, Kivlehan S, Losonczy LI, et al. Critical care service delivery across healthcare systems in lowincome and low-middle-income countries: protocol for a systematic review. BMJ Open 2021;11:e048423. doi:10.1136/ bmjopen-2020-048423

- Prepublication history and online additional supplemental material for this paper are available online. To view these files, please visit the journal online. To view these files, please visit the journal online (http://dx.doi.org/10.1136/ bmjopen-2020-048423).

NKA and TR contributed equally.

NKA and TR are joint senior authors.

Received 30 December 2020 Accepted 21 June 2021

Check for updates

(c) Author(s) (or their employer(s)) 2021. Re-use permitted under CC BY-NC. No commercial re-use. See rights and permissions. Published by BMJ.

For numbered affiliations see end of article.

Correspondence to Dr Andrew George Lim; andrewglim@gmail.com

\section{ABSTRACT}

Introduction Critical care in low-income and lowmiddle income countries (LLMICs) is an underdeveloped component of the healthcare system. Given the increasing growth in demand for critical care services in LLMICs, understanding the current capacity to provide critical care is imperative to inform policy on service expansion. Thus, our aim is to describe the provision of critical care in LLMICs with respect to patients, providers, location of care and services and interventions delivered.

Methods and analysis We will search PubMed/MEDLINE, Web of Science and EMBASE for full-text original research articles available in English describing critical care services that specify the location of service delivery and describe patients and interventions. We will restrict our review to populations from LLMICs (using 2016 World Bank classifications) and published from 1 January 2008 to 1 January 2020. Two-reviewer agreement will be required for both title/abstract and full text review stages, and rate of agreement will be calculated for each stage. We will extract data regarding the location of critical care service delivery, the training of the healthcare professionals providing services, and the illnesses treated according to classification by the WHO Universal Health Coverage Compendium.

Ethics and dissemination Reviewed and exempted by the Stanford University Office for Human Subjects Research and IRB on 20 May 2020. The results of this review will be disseminated through scholarly publication and presentation at regional and international conferences. This review is designed to inform broader WHO, International Federation for Emergency Medicine and partner efforts to strengthen critical care globally. PROSPERO registration number CRD42019146802.

\section{INTRODUCTION}

Acute illness can occur at any point in the healthcare system, and requires recognition,

\section{Strengths and limitations of this study}

To our knowledge, this will be the first systematic review of published literature to comprehensively describe the spectrum of critical care services in healthcare settings across low-income and lowermiddle-income countries.

- We will use standard methods (comprehensive search, training exercises for reviewers, iterative process for conflict resolution) to maximise the rigour of this review.

- A multidisciplinary and multinational team identified through WHO and International Federation for Emergency Medicine networks will conduct this review.

- The scope of the review question is large, which will help to inform public policy but does not allow for meta-analysis to answer a focused clinical question.

- There is a large number of reviewers involved in article selection, such that the threshold for inclusion of studies in the review may vary by reviewer pair and may lead to underestimation of the types or characteristics of critical care services delivered.

resuscitation and stabilisation, along with definitive care. The WHO Emergency Care Systems Framework (ECSF) characterises acute illness as disease or injury processes in which delays can '...worsen prognosis or render care less effective'. ${ }^{1}$ This broad scope requires multiple healthcare partners in an integrated system to triage acuity, transport patients and manage acute illness with infrastructure and personnel. Patients with acute illness often receive critical care, which includes interventions to support failing 
organ systems and prevent further deterioration while the underlying disease is treated. ${ }^{2}$ Critical care interventions vary in technical complexity and location of delivery. Although mechanical ventilation in an intensive care unit (ICU) is a classic example, supplemental oxygen, intravenous fluids and close monitoring and assessment by nurses and physicians all contribute to the maintenance of basic physiological functions. ${ }^{34}$

\section{Critical care services in low-resource settings}

Critical illness is thought to have a higher incidence and mortality in low-income and low-middle-income countries (LLMICs) ${ }^{5-7}$ as shown recently with Global Burden of Disease data for sepsis. ${ }^{8}$ The burden is expected to grow because of increasing urbanisation, incidence of non-communicable disease and injury, and population life expectancy. The higher burden of critical illness in LLMICs is not matched by capacity in equipment, infrastructure and healthcare workforce number and education $^{9-15}$ leading to excess mortality ${ }^{16}$ that is not well documented because of poor epidemiological data and clinical research. ${ }^{1718}$ Because of the lack of ICU capacity, critically ill patients may be managed in non-traditional environments, including hospital wards, emergency care units or in prehospital settings.

\section{Objectives}

The primary objective of our systematic review is to characterise the range of critical care services and interventions delivered across the healthcare system in LLMICs by reviewing reports published from 1 January 2008 to 1 January 2020. We aim to characterise the health service location in which these services or interventions are delivered, the healthcare professionals involved, and the conditions being treated.

\section{METHODS}

\section{Eligibility criteria}

Studies will be eligible for inclusion if they meet the following criteria:

1. Study design: original, peer-reviewed research articles (including cross-sectional, case-control and cohort studies, randomised controlled trials, qualitative methods and mixed-methods studies) and systematic reviews that describe critical care services as defined below. We will exclude case reports and series, study protocols, studies available only as abstracts (eg, conference abstracts, poster presentations, etc), and other unpublished studies. We will only include studies with online full-text availability.

2. Setting: LLMICs, as per the 2016 World Bank classification (table 1). We decided to use the 2016 World Bank classification as a reference point, as the earlier classification is likely to capture more accurately the LLMICs during the time period from which the included studies originate (2008-2020). Within LLMICs, we will include studies that describe the location of delivery
Table 1 List of World Bank low-income to lower-middleincome countries - July 2016

\begin{tabular}{|c|c|c|}
\hline Country & Region & World Bank class \\
\hline Afghanistan & South Asia & Low income \\
\hline Armenia & Europe and Central Asia & $\begin{array}{l}\text { Lower middle } \\
\text { income }\end{array}$ \\
\hline Bangladesh & South Asia & $\begin{array}{l}\text { Lower middle } \\
\text { income }\end{array}$ \\
\hline Benin & Sub-Saharan Africa & Low income \\
\hline Bhutan & South Asia & $\begin{array}{l}\text { Lower middle } \\
\text { income }\end{array}$ \\
\hline Bolivia & $\begin{array}{l}\text { Latin America and } \\
\text { Caribbean }\end{array}$ & $\begin{array}{l}\text { Lower middle } \\
\text { income }\end{array}$ \\
\hline Burkina Faso & Sub-Saharan Africa & Low income \\
\hline Burundi & Sub-Saharan Africa & Low income \\
\hline Cabo Verde & Sub-Saharan Africa & $\begin{array}{l}\text { Lower middle } \\
\text { income }\end{array}$ \\
\hline Cambodia & East Asia and Pacific & $\begin{array}{l}\text { Lower middle } \\
\text { income }\end{array}$ \\
\hline Cameroon & Sub-Saharan Africa & $\begin{array}{l}\text { Lower middle } \\
\text { income }\end{array}$ \\
\hline $\begin{array}{l}\text { Central African } \\
\text { Republic }\end{array}$ & Sub-Saharan Africa & Low income \\
\hline Chad & Sub-Saharan Africa & Low income \\
\hline Comoros & Sub-Saharan Africa & Low income \\
\hline Congo, Dem. Rep. & Sub-Saharan Africa & Low income \\
\hline Congo, Rep. & Sub-Saharan Africa & $\begin{array}{l}\text { Lower middle } \\
\text { income }\end{array}$ \\
\hline Côte d'Ivoire & Sub-Saharan Africa & $\begin{array}{l}\text { Lower middle } \\
\text { income }\end{array}$ \\
\hline Djibouti & $\begin{array}{l}\text { Middle East and North } \\
\text { Africa }\end{array}$ & $\begin{array}{l}\text { Lower middle } \\
\text { income }\end{array}$ \\
\hline Egypt, Arab Rep. & $\begin{array}{l}\text { Middle East and North } \\
\text { Africa }\end{array}$ & $\begin{array}{l}\text { Lower middle } \\
\text { income }\end{array}$ \\
\hline El Salvador & $\begin{array}{l}\text { Latin America and } \\
\text { Caribbean }\end{array}$ & $\begin{array}{l}\text { Lower middle } \\
\text { income }\end{array}$ \\
\hline Eritrea & Sub-Saharan Africa & Low income \\
\hline Ethiopia & Sub-Saharan Africa & Low income \\
\hline Gambia, The & Sub-Saharan Africa & Low income \\
\hline Ghana & Sub-Saharan Africa & $\begin{array}{l}\text { Lower middle } \\
\text { income }\end{array}$ \\
\hline Guatemala & $\begin{array}{l}\text { Latin America and } \\
\text { Caribbean }\end{array}$ & $\begin{array}{l}\text { Lower middle } \\
\text { income }\end{array}$ \\
\hline Guinea & Sub-Saharan Africa & Low income \\
\hline Guinea-Bissau & Sub-Saharan Africa & Low income \\
\hline Haiti & $\begin{array}{l}\text { Latin America and } \\
\text { Caribbean }\end{array}$ & Low income \\
\hline Honduras & $\begin{array}{l}\text { Latin America and } \\
\text { Caribbean }\end{array}$ & $\begin{array}{l}\text { Lower middle } \\
\text { income }\end{array}$ \\
\hline India & South Asia & $\begin{array}{l}\text { Lower middle } \\
\text { income }\end{array}$ \\
\hline Indonesia & East Asia and Pacific & $\begin{array}{l}\text { Lower middle } \\
\text { income }\end{array}$ \\
\hline Kenya & Sub-Saharan Africa & $\begin{array}{l}\text { Lower middle } \\
\text { income }\end{array}$ \\
\hline
\end{tabular}

Continued 
Table 1 Continued

\begin{tabular}{|c|c|c|}
\hline Country & Region & World Bank class \\
\hline Kiribati & East Asia and Pacific & $\begin{array}{l}\text { Lower middle } \\
\text { income }\end{array}$ \\
\hline $\begin{array}{l}\text { Korea, Dem. } \\
\text { People's Rep. }\end{array}$ & East Asia and Pacific & Low income \\
\hline Kosovo & Europe and Central Asia & $\begin{array}{l}\text { Lower middle } \\
\text { income }\end{array}$ \\
\hline Kyrgyz Republic & Europe and Central Asia & $\begin{array}{l}\text { Lower middle } \\
\text { income }\end{array}$ \\
\hline Lao PDR & East Asia and Pacific & $\begin{array}{l}\text { Lower middle } \\
\text { income }\end{array}$ \\
\hline Lesotho & Sub-Saharan Africa & $\begin{array}{l}\text { Lower middle } \\
\text { income }\end{array}$ \\
\hline Liberia & Sub-Saharan Africa & Low income \\
\hline Madagascar & Sub-Saharan Africa & Low income \\
\hline Malawi & Sub-Saharan Africa & Low income \\
\hline Mali & Sub-Saharan Africa & Low income \\
\hline Mauritania & Sub-Saharan Africa & $\begin{array}{l}\text { Lower middle } \\
\text { income }\end{array}$ \\
\hline $\begin{array}{l}\text { Micronesia, Fed. } \\
\text { Sts. }\end{array}$ & East Asia and Pacific & $\begin{array}{l}\text { Lower middle } \\
\text { income }\end{array}$ \\
\hline Moldova & Europe and Central Asia & $\begin{array}{l}\text { Lower middle } \\
\text { income }\end{array}$ \\
\hline Mongolia & East Asia and Pacific & $\begin{array}{l}\text { Lower middle } \\
\text { income }\end{array}$ \\
\hline Morocco & $\begin{array}{l}\text { Middle East and North } \\
\text { Africa }\end{array}$ & $\begin{array}{l}\text { Lower middle } \\
\text { income }\end{array}$ \\
\hline Mozambique & Sub-Saharan Africa & Low income \\
\hline Myanmar & East Asia and Pacific & $\begin{array}{l}\text { Lower middle } \\
\text { income }\end{array}$ \\
\hline Nepal & South Asia & Low income \\
\hline Nicaragua & $\begin{array}{l}\text { Latin America and } \\
\text { Caribbean }\end{array}$ & $\begin{array}{l}\text { Lower middle } \\
\text { income }\end{array}$ \\
\hline Niger & Sub-Saharan Africa & Low income \\
\hline Nigeria & Sub-Saharan Africa & $\begin{array}{l}\text { Lower middle } \\
\text { income }\end{array}$ \\
\hline Pakistan & South Asia & $\begin{array}{l}\text { Lower middle } \\
\text { income }\end{array}$ \\
\hline $\begin{array}{l}\text { Papua New } \\
\text { Guinea }\end{array}$ & East Asia and Pacific & $\begin{array}{l}\text { Lower middle } \\
\text { income }\end{array}$ \\
\hline Philippines & East Asia and Pacific & $\begin{array}{l}\text { Lower middle } \\
\text { income }\end{array}$ \\
\hline Rwanda & Sub-Saharan Africa & Low income \\
\hline Samoa & East Asia and Pacific & $\begin{array}{l}\text { Lower middle } \\
\text { income }\end{array}$ \\
\hline $\begin{array}{l}\text { São Tomé and } \\
\text { Principe }\end{array}$ & Sub-Saharan Africa & $\begin{array}{l}\text { Lower middle } \\
\text { income }\end{array}$ \\
\hline Senegal & Sub-Saharan Africa & Low income \\
\hline Sierra Leone & Sub-Saharan Africa & Low income \\
\hline Solomon Islands & East Asia and Pacific & $\begin{array}{l}\text { Lower middle } \\
\text { income }\end{array}$ \\
\hline Somalia & Sub-Saharan Africa & Low income \\
\hline South Sudan & Sub-Saharan Africa & Low income \\
\hline
\end{tabular}

Continued

\begin{tabular}{|c|c|c|}
\hline Country & Region & World Bank class \\
\hline Sri Lanka & South Asia & $\begin{array}{l}\text { Lower middle } \\
\text { income }\end{array}$ \\
\hline Sudan & Sub-Saharan Africa & $\begin{array}{l}\text { Lower middle } \\
\text { income }\end{array}$ \\
\hline Swaziland & Sub-Saharan Africa & $\begin{array}{l}\text { Lower middle } \\
\text { income }\end{array}$ \\
\hline $\begin{array}{l}\text { Syrian Arab } \\
\text { Republic }\end{array}$ & $\begin{array}{l}\text { Middle East and North } \\
\text { Africa }\end{array}$ & $\begin{array}{l}\text { Lower middle } \\
\text { income }\end{array}$ \\
\hline Tajikistan & Europe and Central Asia & $\begin{array}{l}\text { Lower middle } \\
\text { income }\end{array}$ \\
\hline Tanzania & Sub-Saharan Africa & Low income \\
\hline Timor-Leste & East Asia and Pacific & $\begin{array}{l}\text { Lower middle } \\
\text { income }\end{array}$ \\
\hline Togo & Sub-Saharan Africa & Low income \\
\hline Tonga & East Asia and Pacific & $\begin{array}{l}\text { Lower middle } \\
\text { income }\end{array}$ \\
\hline Tunisia & $\begin{array}{l}\text { Middle East and North } \\
\text { Africa }\end{array}$ & $\begin{array}{l}\text { Lower middle } \\
\text { income }\end{array}$ \\
\hline Uganda & Sub-Saharan Africa & Low income \\
\hline Ukraine & Europe and Central Asia & $\begin{array}{l}\text { Lower middle } \\
\text { income }\end{array}$ \\
\hline Uzbekistan & Europe and Central Asia & $\begin{array}{l}\text { Lower middle } \\
\text { income }\end{array}$ \\
\hline Vanuatu & East Asia and Pacific & $\begin{array}{l}\text { Lower middle } \\
\text { income }\end{array}$ \\
\hline Vietnam & East Asia and Pacific & $\begin{array}{l}\text { Lower middle } \\
\text { income }\end{array}$ \\
\hline $\begin{array}{l}\text { West Bank and } \\
\text { Gaza }\end{array}$ & $\begin{array}{l}\text { Middle East and North } \\
\text { Africa }\end{array}$ & $\begin{array}{l}\text { Lower middle } \\
\text { income }\end{array}$ \\
\hline Yemen, Rep. & $\begin{array}{l}\text { Middle East and North } \\
\text { Africa }\end{array}$ & $\begin{array}{l}\text { Lower middle } \\
\text { income }\end{array}$ \\
\hline Zambia & Sub-Saharan Africa & $\begin{array}{l}\text { Lower middle } \\
\text { income }\end{array}$ \\
\hline Zimbabwe & Sub-Saharan Africa & Low income \\
\hline
\end{tabular}

of critical care services delivered by healthcare professionals in any setting. We will exclude studies describing out-of-hospital settings where care is delivered by lay providers, and critical care delivered in operating rooms as part of a surgical procedure (but will include studies on critical care in preoperative or postoperative care environments). Our rationale is that critical care delivered as part of surgical anaesthesia is often linked to the need for anaesthesia itself rather than to any critical illness. We will exclude studies of military health operations by high-income or high-middleincome country armed forces operating in LLMICs whose treatment populations exclusively consist of military personnel.

3. Participants: any age group.

4. Interventions: critical care services, including medical interventions, diagnostic modalities (including radiology, laboratory testing and microbiology) for the diagnosis or prognostication of critical illness states, 
pharmaceutical services, and healthcare systems-based processes (including advance care planning; coordination of specialist services, critical care triage or care pathways; crisis, surge, mass casualty and disaster management (box 1)). This list reflects a broad perspective of critical care services and is informed by the WHO ECSF $^{19}$

We will include studies that describe critical care service utilisation as a study intervention, exposure or outcome, including studies of capacity building or education if they also involve service delivery for patients. We will exclude simulated interventions.

5. Timing: studies published from 1 January 2008 to 1 January 2020. This date range encompasses the contemporaneous provision of critical care studied before the onset of the global COVID-19 pandemic.

6. Language: studies available in English language through search filters.

\section{Information sources}

Our databases include PubMed/MEDLINE, EMBASE and Web of Science, supplemented by scanning of reference lists of relevant systematic reviews and searches of WHO intranet databases. We will not consider grey literature due to the large scope of the review question and the desire to focus on peer-reviewed studies.

\section{Search strategies}

Literature search strategies were developed by the authors in conjunction with a Stanford University Health Sciences librarian (CDS) with expertise in systematic review searching, with technical support from WHO Library services (TA). We used controlled vocabulary terms and text words related to critical care in LLMICs (see online supplemental appendix 1 for PubMed/MEDLINE search strategy, subsequently adapted to EMBASE and Web of Science). We also searched PROSPERO for ongoing or recently completed systematic reviews. We restricted search results to citations in English pertaining to humans, published from 1 January 2008 to 1 January 2020.

\section{Study records}

Literature search results will be uploaded to Covidence (Covidence, Melbourne, Australia), a web-based online platform that facilitates collaboration among reviewers during systematic review study selection. Full-text articles will be uploaded to Covidence during the full-text review phase.

\section{Selection process}

Reviewers will be unblinded to author and institution details of citations. To maximise consistency in assessing inclusion and exclusion criteria among 21 reviewers, we plan calibration pilot exercises for title and abstract screening and group discussions using Google Groups (Google, Mountain View, California, USA) and online group videoconferencing. This training will emphasise the need for sensitivity in citation selection in the title and abstract phase. Independently and in duplicate, reviewers
Box 1 Critical care service delivery/interventions list

\section{Monitoring/nursing}

- Frequent monitoring/surveillance and recording of clinical parameters (vital signs, pulse oximetry, capnography, etc).

- Acuity-based triage/performance of focused assessment for the critically ill (including shock, altered mental status, respiratory distress, polytrauma, etc).

- Critical care nursing services (including implementation of higher than floor/ward-level care or nurse:patient ratio).

- Frequent monitoring/surveillance of fetus (fetal heart monitoring, tocometry, etc).

Interventions for haemodynamic instability/organ dysfunction

- Support of haemodynamic instability and management of acute life threatening organ dysfunction.

- Titration of advanced parenteral therapeutics.

- Intravenous fluid resuscitation.

- Blood products transfusion.

- Administration of advanced blood replacement therapies (eg, plasmapheresis).

- Massive haemorrhage control (including tourniquet application, haemostatic agents, pelvic binding).

- Targeted temperature management and hyperthermia/hypothermia management.

- Vasopressor/inotrope administration.

- Antiarrhythmic medication administration for the critically ill.

- Cardiopulmonary resuscitation, basic only (chest compressions in the absence of invasive procedures).

- Advanced cardiac life-support resuscitation (include emergent pacing, defibrillation, cardioversion).

- Spinal immobilisation.

- Extracorporeal membrane oxygenation/extracorporeal life support.

- Advanced trauma resuscitation/Advanced Trauma Life Support/WHO Trauma Care Checklist use.

Respiratory interventions

- Support of respiratory insufficiency/failure.

- 0xygen delivery, simple (face mask, nasal prongs).

- Oxygen delivery, high flow (>15L/min).

- Mechanical ventilation, non-invasive (including continuous positive airway pressure).

- Mechanical ventilation, invasive.

- Non-invasive airway management (basic airway opening maneuversmanoeuvres, bag mask ventilation, oropharyngeal or nasopharyngeal airway placement, etc).

- Advanced invasive airway management, non-surgical (tracheal intubation, laryngeal mask airway placement, bougie, airway exchange catheters, etc).

- Advanced surgical airway management (tracheostomy, cricothyrotomy performed outside the operating room/theatre).

Other invasive procedures

- Peripheral venous cannulation for the critically ill.

- Advanced vascular access (arterial lines, central venous/pulmonary artery catheters, intraosseous access).

- Thoracic invasive procedures for the critically ill (thoracostomy, pleural drain placement, thoracentesis, pericardiocentesis, emergent thoracotomy performed outside of the operating room/theatre).

\section{Additional targeted therapies}

- Early antibiotic administration for the critically ill.

- Treatment of severe infections/inflammation/sepsis (steroids and other adjuncts).

Renal replacement therapy/haemodialysis or peritoneal dialysis. 


\section{Box 1 Continued}

- Monitoring and treatment of critical electrolyte/metabolic/acid base derangements.

- Nutrition management for the critically ill/injured.

- Provision of prophylaxis associated with critical illness (including alimentary, venous thromboembolism).

- Advanced burn care for the critically ill.

- Emergent poisoning detoxification/antidote.

- Acute reperfusion therapy: medical or interventional (cardiac/coronary arteries).

- Acute reperfusion therapy: medical or interventional (pulmonary embolism or other acute thromboembolism).

Neurological interventions

- Acute medical stabilisation of critical neurological illness/provision of neuroprotection for the critically ill (eg, seizure management).

- Acute surgical stabilisation of critical neurological illness (eg, emergent craniotomy, ventricular drain, intracranial pressure monitor performed outside the operating room/theatre).

- Acute management of agitation/delirium.

- Acute reperfusion therapy: medical or interventional (neurovascular procedures for cerebrovascular pathology such as stenting, coiling performed outside the operating room/theatre).

- Analgesia and sedation (sedative infusions, moderate/conscious sedation, up to general anaesthesia, performed outside the operating room/theatre).

\section{Obstetrical critical care services}

Obstetric critical care management (induction, tocolytic, high-risk labour, emergent/complex delivery, perimortem caesarean section performed outside the operating room/theatre).

\section{Diagnostic modalities}

- Utilisation of targeted diagnostic strategy to establish timely aetiology for the critically ill.

Basic radiography.

$\rightarrow$ CT.

$>$ MRI.

- Critical care ultrasound, including point-of-care transthoracic/transoesophageal echocardiography.

- Laboratory and other rapid results reporting including pointof-care diagnostics (arterial blood gas, glucometry, chemistry, haematology).

- Microbiology and other infectious rapid results reporting.

Multi-system processes related to critical care service delivery

- Prognosis-based advance care planning (critical care level hospice/ palliative, goals of care discussions, plan for de- escalation of care and transition to post-critical care needs appropriate to context).

- Coordination of specialist services for multisystem illness (managing communication between, and coordination of, various healthcare personnel caring for patient detailing diagnosis, treatment given and disposition).

- Critical care triage/care pathways systems/clinical illness severity and/or risk stratification.

- Critical care level crisis management (surge response, disaster management, multiple casualty incident).

- Health information systems, medical records.

Other critical care services

- Critical care pharmacy services.

- Critical care education and capacity building (must have clinical service delivery component).

- Other critical care intervention/service delivery will screen titles and abstracts for potentially relevant studies using Covidence. Because of the anticipated very large number of potentially relevant citations, the agreement of two members of the review team will be required for citation selection at the title and abstract phase; disagreements will be adjudicated by a third reviewer.

Full-text versions of citations included at the title and abstract screening phase will be retrieved and reviewed by the same team of reviewers. If full text is not retrievable by at least two reviewers, including efforts to contact the study authors directly, the study will be excluded as unavailable. If retrieved citations are found to be abstract-only, they will be excluded, but we will search for any subsequent peer-reviewed journal publications not already captured by our search. The agreement of two reviewers will be required for inclusion of the full-text study in the systematic review, with conflicts resolved by a third reviewer experienced with this review process. Reasons for full-text exclusion will be recorded (table 2).

\section{Data extraction}

Individual reviewers will extract data from selected articles using Excel (Microsoft, Redmond, Washington, USA). The data sheet underwent multiple iterations, informed by pilot testing on selected articles and group discussion. A review group member will review each cluster of data entry for consistency of data extraction.

We will extract data on the study design, LLMIC country or countries involved, article identifiers, location(s) within the healthcare system that critical care service(s) were delivered, healthcare provider(s) providing the service(s), the critical care service(s) provided, critical illnesses addressed, sample size, and the age range of the study population. Given the clinical heterogeneity of patient populations and interventions, we will not extract data on patient outcomes or the number of critical care beds in a given study facility.

Critical care services will be identified using international professional society definitions and the scope of critical care functions in the WHO ECSF. Services will be subsequently classified based on the categories in the WHO Universal Health Coverage (UHC) Compendium. ${ }^{20}$ We will use the top level architecture of the compendium to categorise services broadly into foundations of care, reproductive and sexual health, nutrition, end-of-life and palliative care issues, violence and injury, non-communicable diseases (including diseases of the cardiovascular, respiratory, neurologic, endocrine/metabolic, immunological, digestive, haematological, genitourinary and other systems) and communicable diseases.

\section{Limitations}

A potential overall source of bias in this review is the large number of reviewers involved in article selection, such that the threshold for inclusion of studies in the review may vary by reviewer pair and may lead to an underestimation of the locations or types of critical care services delivered. We 


\begin{tabular}{ll}
\hline Table 2 & Hierarchy of exclusion for full text \\
\hline 1 & Not published from 1 January 2008 to 1 January 2020 \\
2 & Is not a study on living humans, or is not related to health aspects of living humans (exclude animal or forensic studies) \\
3 & Does not address low-income or low-middle-income country (per World Bank Class 2016) \\
4 & Does not address critical care service/interventions (per box 1) \\
5 & Not original research, systematic review or brief report \\
6 & Does not describe where in healthcare setting critical care service/intervention is delivered \\
7 & Addresses exclusively perioperative care that occurs in the operating room/theatre \\
8 & Does not address care by healthcare professionals \\
9 & Addresses care performed exclusively by or for high-income country/high-middle-income country military personnel \\
10 & Abstract-only, full text non-existent (for conference, poster/presentation, etc) \\
11 & Full text not available in English \\
12 & Full text not available online \\
\hline
\end{tabular}

have attempted to mitigate this bias by extensive training of reviewers as described above.

Our study does not include publications on critical care delivery during the COVID-19 pandemic, and characteristics of care delivery may have changed over that time.

\section{Risk of bias}

Given the broad scope of the review, anticipated heterogeneous studies (regarding design, population. methods and outcomes), and lack of planned meta-analyses to calculate summary effects of associations between exposures and outcomes, we will not assess the risk of bias (ROB) of individual studies. ROB of included studies is crucial to assess when conducting a systematic review of therapeutic outcomes, diagnosis, natural history, prognosis or clinical prediction. However, for this study, we aim to describe the location of critical care delivery and the specific services and interventions delivered. Although a complete sample of published literature within our time frame of interest is crucial, we believe that assessing the $\mathrm{ROB}$ of each included study is not relevant to our intended review objectives.

\section{Data analysis}

We will calculate summary descriptive statistics, using counts and proportions for categorical data and means (SD) or median (Q1, Q3) for continuous data. We will describe the number of publications by year, types of services delivered, healthcare provider type, location of service delivery, study population age group and critical illness category (based on the WHO UHC Compendium), stratified by World Bank income class and WHO region. Due to the descriptive nature of the study question and expected heterogeneity of patients and interventions, no meta-analyses of effects on patient outcomes are planned. We anticipate that narrative synthesis may be required to summarise our study results. We will conduct a sensitivity analysis to separately consider studies that report only on adults and studies only on children.

Subsequent ancillary reviews based on this dataset of studies may investigate specific age group populations, continents/regions, World Bank classes, critical care intervention clusters, disease groups, locations or healthcare professionals involved.

\section{Ethics and dissemination}

The study protocol was reviewed and exempted by the Stanford University Office for Human Subjects Research and Institutional Review Board (IRB) on 20 May 2020. The results of this review will be disseminated through scholarly publication and presentation at regional and international conferences. This review is designed to inform broader WHO, International Federation for Emergency Medicine and partner efforts to strengthen critical care globally.

We anticipate that the results of this comprehensive review will describe the current scope of critical care services, providers and location of service delivery in LLMICs, and will provide a database of pertinent literature for future studies. The results of the review will be instrumental for planners and policy makers in developing critical care service infrastructure, funding priorities and capacity-building interventions, and will highlight gaps in current knowledge of critical care service delivery in LLMICs.

\section{Author affiliations}

${ }^{1}$ Section of Critical Care Medicine, Virginia Mason Medical Center, Seattle, Washington, USA

${ }^{2}$ Division of Critical Care Medicine, Stanford University, Stanford, California, USA ${ }^{3}$ Department of Emergency Medicine, Brigham and Women's Hospital, Boston, Massachusetts, USA

${ }^{4}$ Department of Emergency Medicine, Harvard University, Cambridge, Massachusetts, USA

${ }^{5}$ Department of Emergency Medicine, Department of Anaesthesia \& Critical Care Medicine, The George Washington University Medical Center, Washington, District of Columbia, USA

${ }^{6}$ Department of Paediatrics, University of British Columbia, Vancouver, British Columbia, Canada

${ }^{7}$ Emergency Medicine Research Group, Anglia Ruskin University, Chelmsford, UK ${ }^{8}$ Department of Critical Care Medicine, Department of Emergency Medicine, Mid Cheshire Hospitals NHS Foundation Trust, Cheshire, UK

${ }^{9}$ Accident and Emergency Medicine, The Chinese University of Hong Kong Faculty of Medicine, Hong Kong, Hong Kong

${ }^{10}$ Department of Emergency Medicine, Baylor College of Medicine, Houston, Texas, USA

${ }^{11}$ Department of Emergency Medicine, Intensive Care \& Resuscitation, Cleveland Clinic Foundation, Cleveland, Ohio, USA 
${ }^{12}$ Division of Pulmonary \& Critical Care Medicine, Washington University School of Medicine in Saint Louis, Saint Louis, Missouri, USA

${ }^{13}$ Department of Emergency Medicine, University of Michigan Medical School, Ann Arbor, Michigan, USA

${ }^{14}$ Department of Emergency Medicine, University of Washington, Seattle, Washington, USA

${ }^{15}$ Department of Emergency Medicine, The George Washington University Hospital, Washington, District of Columbia, USA

${ }^{16}$ The George Washington University School of Medicine and Health Sciences, Washington, District of Columbia, USA

${ }^{17}$ Department of Emergency Medicine, East Avenue Medical Center, Quezon City, National Capital Region, Philippines

${ }^{18}$ Department of Emergency Medicine, University of California San Francisco, San Francisco, California, USA

${ }^{19}$ Department of Medicine, Stanford University, Palo Alto, California, USA

${ }^{20}$ Department of Emergency Medicine, Jacobi Medical Center, Bronx, New York, USA

${ }^{21}$ Division of Pulmonary \& Critical Care Medicine, Brigham and Women's Hospital,

Boston, Massachusetts, USA

${ }^{22}$ Division of Pulmonary and Critical Care Medicine, Department of Medicine,

Harvard Medical School, Boston, Massachusetts, USA

${ }^{23}$ Department of Emergency Medicine, Harvard Medical School, Boston,

Massachusetts, USA

${ }^{24}$ Department of Emergency Medicine, Mount Sinai Hospital, New York, New York, USA

${ }^{25}$ Emergency Medicine, The George Washington University School of Medicine and Health Sciences, Washington, District of Columbia, USA

${ }^{26}$ Department of Emergency Medicine, University of California Los Angeles, Los Angeles, California, USA

${ }^{27}$ Department of Critical Care Medicine, Sunnybrook Health Sciences Centre and

University of Toronto, Toronto, Ontario, Canada

${ }^{28}$ World Health Organization, Geneva, GE, Switzerland

Twitter Andrew George Lim @andrewglim, Srinivas Murthy @srinmurthy99, Enrico Dippenaar @EnricoDippenaar, Sojung Yi @sojung_yi and Paul D Sonenthal @ psonenthal

Acknowledgements We would like to thank Christopher Donald Stave (Stanford University Library Services) and Tomas Allen (WHO Library) for their assistance in developing the literature search strategy and Elsa Courdier (WHO) for manuscript preparation. Other technical support was provided by the International Federation for Emergency Medicine (IFEM), and the IFEM Special Interest Group for Critical Care in Emergency Medicine.

Contributors AGL is the guarantor, drafted, prepared and submitted the manuscript, contributed to the development of the selection criteria, methodology, data extraction criteria and forms, developed and executed the search strategy, provided teaching and guidance of review process to review group. NA, SM, SK, LIL, ED, BAC, NB, AB, MSJ, PDS and TR provided comments and critical revisions to the manuscript, made substantial contributions to the conception and design of the review methodology and planned analysis. ED, SK, PAS, MLCLCY, BAC, PDS, MSJ, RL, AG-R, CAC, NB, NH, NS, PM, BPV, NS, AB, CM, AGR, ESB, AF and SY made key contributions to the conception, design and execution of eligibility criteria and methodology, participated in the acquisition and interpretation of reference data for screening phases, provided feedback on full text data extraction forms, and provided critical edits to the intellectual content of the manuscript.All authors read, provided feedback and approved the final manuscript, and agree to be accountable for all aspects of the work in ensuring that questions related to the accuracy or integrity of any part of the work are appropriately investigated and resolved. Thus, all authors have met the four ICMJE criteria recommended for authorship.

Funding The authors have not declared a specific grant for this research from any funding agency in the public, commercial or not-for-profit sectors.

Competing interests None declared.

Patient and public involvement statement No patients were involved in this study.

Patient consent for publication Not required.

Provenance and peer review Not commissioned; externally peer reviewed.

Supplemental material This content has been supplied by the author(s). It has not been vetted by BMJ Publishing Group Limited (BMJ) and may not have been peer-reviewed. Any opinions or recommendations discussed are solely those of the author(s) and are not endorsed by BMJ. BMJ disclaims all liability and responsibility arising from any reliance placed on the content. Where the content includes any translated material, BMJ does not warrant the accuracy and reliability of the translations (including but not limited to local regulations, clinical guidelines, terminology, drug names and drug dosages), and is not responsible for any error and/or omissions arising from translation and adaptation or otherwise.

Open access This is an open access article distributed in accordance with the Creative Commons Attribution Non Commercial (CC BY-NC 4.0) license, which permits others to distribute, remix, adapt, build upon this work non-commercially, and license their derivative works on different terms, provided the original work is properly cited, appropriate credit is given, any changes made indicated, and the use is non-commercial. See: http://creativecommons.org/licenses/by-nc/4.0/.

\section{ORCID iDs}

Andrew George Lim http://orcid.org/0000-0002-3374-7659

Sean Kivlehan http://orcid.org/0000-0002-4857-4316

Marc Li Chuan L C Yang http://orcid.org/0000-0002-0829-5339

Michael S Jaung http://orcid.org/0000-0002-6722-4557

Neill KJ Adhikari http://orcid.org/0000-0003-4038-5382

\section{REFERENCES}

1 Reynolds T, Sawe H, Rubiano A. Strengthening Health Systems to Provide Emergency Care. In: Disease control priorities: improving health and reducing poverty. 3rd edition. Washington, DC: The International Bank for Reconstruction and Development/The World Bank, 2017. https://www.ncbi.nlm.nih.gov/books/NBK525279/

2 Marshall JC, Bosco L, Adhikari NK, et al. What is an intensive care unit? A report of the task force of the world Federation of societies of intensive and critical care medicine. J Crit Care 2017;37:270-6.

3 Herbert LJ, Wilson IH. Pulse oximetry in low-resource settings. Breathe 2012;9:90-8.

4 Cameron PA, Gabbe BJ, Smith K, et al. Triaging the right patient to the right place in the shortest time. Br J Anaesth 2014;113:226-33.

5 Diaz JV, Riviello ED, Papali A, et al. Global critical care: moving forward in resource-limited settings. Ann Glob Health 2019;85. doi:10.5334/aogh.2413. [Epub ahead of print: 2201 2019].

6 Murthy S, Adhikari NK. Global health care of the critically ill in lowresource settings. Ann Am Thorac Soc 2013;10:509-13.

7 Mathers C, Fat DM, Boerma JT. The global burden of disease: 2004 update. Geneva, Switzerland World Health Organization; 2008.

8 Rudd KE, Johnson SC, Agesa KM, et al. Global, regional, and national sepsis incidence and mortality, 1990-2017: analysis for the global burden of disease study. Lancet 2020;395:200-11.

9 Schultz MJ, Dunser MW, Dondorp AM, et al. Current challenges in the management of sepsis in ICUs in resource-poor settings and suggestions for the future. Intensive Care Med 2017;43:612-24.

10 Murthy S, Leligdowicz A, Adhikari NKJ. Intensive care unit capacity in low-income countries: a systematic review. PLoS One 2015:10:e0116949.

11 Murthy S, Adhikari NK. Global health care of the critically ill in lowresource settings. Ann Am Thorac Soc 2013;10:509-13.

12 Duke T, Graham SM, Cherian MN. Oxygen is an essential medicine: a call for international action. Int J Tuberc Lung Dis 2010;14:1362-8.

13 Hansmann A, Morrow BM, Lang H-J. Review of supplemental oxygen and respiratory support for paediatric emergency care in sub-Saharan Africa. Afr J Emerg Med 2017;7:S10-19.

14 Thaddeus S, Maine D. Too far to walk: maternal mortality in context. Soc Sci Med 1994;38:1091-110.

15 Cavallaro FL, Marchant TJ. Responsiveness of emergency obstetric care systems in low- and middle-income countries: a critical review of the "third delay". Acta Obstet Gynecol Scand 2013;92:496-507.

16 Shanahan T, Risko N, Razzak J, et al. Aligning emergency care with global health priorities. Int J Emerg Med 2018;11:1-4.

17 Mehmood A, Razzak JA, Kabir S, et al. Development and pilot implementation of a locally developed trauma registry: lessons learnt in a low-income country. BMC Emerg Med 2013;13.

18 Reynolds TA, Stewart B, Drewett I, et al. The impact of trauma care systems in low- and middle-income countries. Annu Rev Public Health 2017;38:507-32.

19 World Health Organization. Who emergency care systems framework. Available: https://www.who.int/publications/i/item/whoemergency-care-system-framework

20 World Health Organization. Who universal health coverage compendium. Available: https://www.who.int/universal-healthcoverage/compendium 